\title{
Suitability of Blackboard as Learning Management System to assess oral competence: Students' perceptions and results
}

\author{
Ana Isabel Muñoz Alcón ${ }^{1}$, Francisco Trullén Galve ${ }^{2}$ \\ ${ }^{1}$ Department of Humanities and Education, Catholic University Saint Teresa of Avila, Spain, \\ ${ }^{2}$ Department of Law and Social Sciences, Catholic University Saint Teresa of Avila, Spain.
}

\begin{abstract}
Learning a foreign language involves the practice and development of linguistic competencies through a series of communicative activities. Assessing each of these competencies face to face can provide an accurate profile of the student's level of language proficiency. But assessing them online, particularly oral skill, poses a challenge for both students and professors. The change of scenario and use of digital tools may intimidate students and deprive the interview from naturality and warmth. In this paper, the suitability of Blackboard Collaborate as Learning Management System to assess English speaking skill is studied together with other factors influencing students' online performance. 81 students from 5 different undergraduate programs in Engineering and Applied Sciences were assessed, following the threefold pattern of IELTS speaking test questions (International English Language Testing System). Their results and responses to a final survey are contrasted so as to check the positive of negative effect of online testing on the students'state of mind and eventual achievement. Blackboard platform proves to be as a suitable online framework for optimal performance, and the examiner's attitude is equally a conditioning factor in students'success.
\end{abstract}

Keywords: Assessment; speaking skill; oral competence; Learning Management System (LMS); online platform; Blackboard. 


\section{Introduction}

The achievement of learning goals in foreign language learning must be checked by means of consistent assessment types and reliable tools which reveal the students' actual level of linguistic competences. Apart from the numerous ways of standardized testing which are currently widely applied in order to certify individuals' proficiency level in a language, new forms of formative assessment have sprung at university level to check students' language learning. Standardized tests have found in online formats a suitable and profitable way to give access to greater number of students to certified exams together with a means of facilitating and shortening the grading time. Both easy access and time-saving procedures, as well as proven validity, are nowadays among the most valued features in standardized testing. Focusing on English as a foreign language (EFL) at Higher Education (HE), learning of a foreign language is usually incorporated into the curriculum as part of undergraduate programs in the form of English for specific purposes (ESP). No matter what specific field of study English is taught, foreign language (FL) is learnt in a much more contextualized and personalized environment. Learning goals are not restricted to linguistic skills but they also include a carefully selected range of competencies to be developed throughout the learning period. Students' practice of the language with a communicative purpose, guided by the specialized professor, proves to be a valuable source of information and reciprocal feedback. Foreign language learning in this context is a natural process where interpersonal communication is an important part and where not only linguistic skills are developed but other non-linguistic skills. These university scenarios where ESP is learnt make it easier for professors to assess students and, in turn, the latter find them safe environments to be assessed.

The growth of universities and spreading of students into different campuses meant a challenge for higher education programs. In particular, many universities, forced by the Covid-19 pandemic, risked themselves to transform most -if not all- their programs into an online modality. This fact has meant not only a great investment of resources and effort, but also a launching of online courses supported by different Learning Management Systems (LMS). In the case of foreign languages, the theoretical content of which is scarce compared to the practical content, this transformation has posed a real challenge. LMS offer many utilities for the presentation of contents and, very often, features to let students practice the language both orally and in written form (Rodrigues and Vethamani, 2015). But online platforms lack the closeness and warmth of personal face-to-face communication (Jordan and Duckett, 2018). As regards skills and competencies involved in FL learning, educational researchers recognize the difficulty to assess them, especially oral ones, in online environments (Babo, Azevedo and Suhonen, 2015). 


\section{Objectives}

The main objectives of this study are the following:

1. Check if Blackboard is a reliable LMS to assess oral competence of English for Specific Purposes (ESP) students.

2. Check if Blackboard is technically efficient for speaking assessment

3. Find out which other factors -apart from the platform efficiency- may influence students' speaking performance.

4. Know the students' perception of possible advantages of Blackboard compared to face-to-face speaking assessment.

\section{Context and test group}

ESP is a 6-credit obligatory subject taken by all university students over a semester at UCAV (Catholic University St Teresa of Avila, Spain). An intermediate level of English (B1-B1+) (according to the Common European Framework of Reference for Languages, CEFR) is to be achieved in each of the undergraduate programs. It is academic English with specific language referred to the different fields of study. Participants in the present research were all students taking English as a foreign language (EFL) in Forestry, Agricultural and Mechanical Engineering (60\%), Environmental Sciences (17\%) and Psychology (23\%). Test group consisted of 81 undergraduate students, 54 were men (66.6\%) and 27 women (33.3\%). Table 1 shows age composition of the test group.

Table 1. Test group composition by age.

\begin{tabular}{ccccc}
\hline Age range & $\mathbf{1 9 - 2 9}$ & $\mathbf{3 0 - 3 9}$ & $\mathbf{4 0 - 4 9}$ & $>\mathbf{5 0}$ \\
\hline Percentage & $44.3 \%$ & $30 \%$ & $22.9 \%$ & $2.8 \%$ \\
\hline
\end{tabular}

All 81 students took a speaking test at the end of the semester, as part of their FL final exam, via an online platform.

ESP courses were delivered online using Blackboard as Learning Management System (LMS). The specific version supporting instruction was Blackboard Learn 3800 (Blackboard Collaborate Ultra), which offers a wide range of functionalities for FL teaching and learning and, in particular, the development and assessment of oral competence. The choice of Blackboard Learn 3800 was due to the fact that it is the LMS used at the Catholic University St Teresa of Avila. Following the distinction that some researchers make within the oral competence, we will specifically focus on the speaking subcompetence of the foreign language, henceforth speaking skill (González-Such, Jornet Meliá and Bakieva, 2013). 


\section{Methodology}

A mixed-method approach (Englund, Olofsson \& Price, 2017) was adopted collecting quantitative and qualitative data. Qualitative data were collected from examiner's observation during the speaking tests, registered session reports, and student responses to open-ended questions included in an anonymous online questionnaire. Quantitative data were provided by a web-based survey of closed questions and from speaking test results.

\subsection{Procedure}

Speaking tests of 81 undergraduate students took place in six different sessions. They were performed individually, in the format of a structured interview between the candidate and the examiner, who was the same professor in all sessions. The students, in turns, entered the virtual classroom on Blackboard platform and the examiner asked the candidate three questions of three different types: (a) open questions referring to personal background or experience; (b) prompts for the candidate to speak on a topic for two minutes; (c) opinionquestions about more general topics. Each performance was recorded and its length was between six to eight minutes on average. A rubric was used for the assessment of a variety of features which are indicators of oral proficiency (González-Such et al, 2013): lexical (vocabulary suitability to the topic and context), morphosyntactic (language usage and discourse structures), phonological (pronunciationa and intonation), sociolinguistic (adequacy to the context and register, and fluency).

After all speaking tests were completed, students were invited to answer an online survey delivered through Google Forms. The survey should be answered anonymously and consisted of 16 items:14 multiple choice and 2 open questions. 70/81 students answered the online survey, which represents a high response rate $(86.4 \%)$.

\section{Results}

Students' responses in the survey reveal that for $37 \%$ of students, it was the first time they had taken a speaking test in FL. Moreover, $83 \%$ of students had never taken a speaking test through an online platform.

Examiner's reported observations on Blackboard technical features are summarized in table 2. They will shed light about how they may have positively or negatively affected students' speaking test. 
Table 2. Observations on Bb technical features during speaking tests.

\begin{tabular}{lll}
\hline $\begin{array}{l}\text { Technical } \\
\text { features }\end{array}$ & Performance & Incidents \\
\hline Image & Synchronic visual interface & $\begin{array}{l}\text { Scarce. Only due to blockers } \\
\text { in student's browser }\end{array}$ \\
Sound & Synchronic sound with no delays & $\begin{array}{l}\text { Very few. Due to student's } \\
\text { faulty Internet connection }\end{array}$ \\
Whiteboard & Usefulness for presenting a topic to talk about & None \\
Chat & Parallel communication support in case of need & None \\
\hline
\end{tabular}

The few incidents (a total of 6) which occurred when some candidates entered the virtual classroom, were sorted out by resorting to change the student's device or moving to another location where internet coverage was better or broadband was available. On those particular cases, access to Blackboard from an iphone never failed. Table 3 shows the range of devices used by students to access the virtual classroom for the speaking test.

Table 3. Digital devices used for speaking test.

\begin{tabular}{lc}
\hline Device & $\mathbf{\%}$ \\
\hline Laptop & $65.7 \%$ \\
PC & $22.9 \%$ \\
Mobile phone & $10 \%$ \\
Tablet & $1.4 \%$ \\
\hline
\end{tabular}

As it was described above, each of the 81 students was asked three different questions in the course of a semi-structured conversation. Presented in a progressive level of difficulty, they aimed at rating the student according to a rubric. They ranged from simpler questions referring to the candidate's personal background, preferences and experience, which build up the person's self confidence (Mishra, 2014), to more complex questions to express their opinion about general issues. Each of the indicators of oral proficiency was scored from 0 to 5 and the total final overall score was calculated and provided on a scale over 10. Speaking tests results 2020-21 are shown in Table 4.

Table 4. Online Speaking Test Results 2020-21.

\begin{tabular}{lcccc}
\hline Students' Program & Mean & Median & Mode & SD \\
\hline Forestry, Agriculture and & 6.9 & 6.25 & 9 & 1.9 \\
Mechanical Engineering & 8.1 & 8 & 8 & 1.4 \\
Environmental Sciences & 6.6 & 6 & 7 & 1.8 \\
Psychology & 7.2 & 7 & 6 & 1.8 \\
\hline Test group globally considered & & &
\end{tabular}


Though mean scores vary depending on the program, figures show high levels of performance. Standard deviation values are low. Only 6 out of 81 students did not achieve the minimal level of speaking competency required for an intermediate level of oral proficiency in English. This represents only 7,5\% of test group in contrast with 92,5\%, percentage of successful students. In order for results from online speaking tests and face-toface speaking tests to be compared, scores from speaking tests taken by Engineering, Environmental Sciences and Psychology undergraduate students -globally considered- in academic years 2017-18, 2018-19 and 2019-20 are shown in table 5.

Table 5. Face-to-face Speaking Test Results 2017-2020.

\begin{tabular}{cccccc}
\hline Academic year & N students & Mean & Median & Mode & SD \\
\hline $2017-18$ & 24 & 6.39 & 6 & 6 & 1.96 \\
$2018-19$ & 29 & 6.85 & 6.4 & 6.4 & 1.64 \\
$2019-20$ & 27 & 7 & 6.8 & 6 & 1.72 \\
\hline
\end{tabular}

When questioned about which modality was preferred for taking a speaking test (online or face-to-face), $7,1 \%$ were indifferent and $68,6 \%$ of respondents expressed their preference for online mode. Table 6 summarizes the reasons for students' test modality prefences.

Table 6. Reasons for student test-mode preferences.

\begin{tabular}{lclc}
\hline Face-to-face & n & Online & n \\
\hline Communication is more natural & 3 & It is more comfortable and practical & 16 \\
Communication is less cold and impersonal & 5 & It makes one feel more comfortable & 4 \\
Communication is more real & 3 & One feels less nervous & 13 \\
The possibility of technical failures adds & 4 & Being at home or personal & 6 \\
anxiety to exam situation. & 2 & It is highly time-saving & 9 \\
Possibility of more non-verbal communication & 2 &
\end{tabular}

Regarding the examiner's non-verbal feedback and attitude during the speaking test, 95,7\% of students stated that her friendly and supportive attitude helped them in their speaking performance. The second open-ended question in the survey was "In general terms, do you think that Blackboard virtual classroom is a suitable means to take a speaking test?". Students' responses reveal that they do consider Blackboard Collaborate Ultra (Bb) a suitable LMS for taking oral exams because of the following reasons:

(a) Optimal audio and video quality

(b) Easy to use, intuitive

(c) Simple to connect and access

(d) Secure for an exam: audiovisual intercommunication with no interruption 
(e) Comfortable and time-saving

(f) Agile and dynamic, with useful features

\section{Conclusions}

The discussion of the results and the main conclusions of the study are organized according to the research objectives. In relation to Objective 1 "Check if Blackboard is a reliable LMS to assess oral competence of English for Specific Purposes (ESP) students", from both the examiner's observation and the student's reponses, it can be concluded that it offers a secure online environment for an oral exam. Audiovisual intercommunication with no interruptions makes it possible continuous interpersonal communication. Likewise, it enables the synchronic completion of different tasks in order to assess the candidate's speaking proficiency at a lexical, grammatical, phonological, discourse and sociolinguistic levels. As other researchers have also pointed out (Irawan, 2020), the possibility of recording the session on the platform lets the examiner replay the video of students' speaking performances in order to focus on students' utterances and speech details. This recording feature facilitates a more accurate assessment of student's speaking skill.

Regarding Objective 2 "Check if Blackboard is technically efficient for speaking assessment", synchronic image and sound with no streaming delays optimize interpersonal communication during the exam. $68,6 \%$ of students expressed their preference for taking their speaking exam through $\mathrm{Bb}$ platform and $98 \%$ recognized its optimal performance during the exam as well as its easy and comfortable use and access. This latter statement is interesting to consider since -as it was shown in the students' age range- not all of them may have a highly developed digital competence, necessary requirement to master and feel selfconfident at using a digital platform (Hussein, 2016). Lastly, the platform versatility makes access possible from every digital device, which adds convenience to its use.

As regards Objective 3 "Find out which other factors -apart from the platform efficiencymay influence students' speaking performance", answers to open question 1 in the survey (i.e. "Which modality do you prefer to take a speaking exam: face-to-face or online?") reveal at least three. Firstly, speaking to the examiner through a camera interposes a "safety barrier" which makes students feel less tense and nervous. $27 \%$ of students who prefer online speaking tests mentioned this favourable factor. Secondly, 12 ' $5 \%$ of students who shared the same online preference, indicated the fact of being located in a familiar place or at home as a contributing factor to relaxation and higher fluency at talking in FL. Thirdly, and most important, $95,7 \%$ of all 70 respondents recognized in the examiner's friendly and supportive attitude a decisive and beneficial factor to lessen psychological barriers in order to speak more confidently in the foreign language. As it was stated by one of respondents in the 
survey, "closeness between student and examiner depends not so much on the digital platform but on the examiner's attitude".

Finally, in relation to Objective 4 "Know the students' perception of possible advantages of $\mathrm{Bb}$ compared to face-to-face speaking assessment", the alleged reasons are -in order of priority- the following: (a) comfort and practicality; (b) talking on the screen facilitates a higher concentration on the tasks and reduces nervousness ; (c) it lets students save a great amount of time since they need not travel or miss other academic or professional activities; (d) the possibility of being examined from home or a familiar environment eases the associated exam situational tension; (e) it lets students feel more comfortable and selfconfident. Overall, online platform Blackboard Collaborate Ultra proves to be a suitable LMS for optimal speaking performance and assessment, and the examiner's attitude is equally a conditioning factor in students' oral competence achievement. Considering that for $83 \%$ of students it was their first speaking test through an online platform, survey responses reveal a high level of satisfaction with the experience as well as with their exam results, which are slightly better than those corresponding to face-to-face speaking tests in previous years. Even though further research should be carried out in order to extend both the number and academic profiles of undergraduate students to be tested using Blackboard, it can be concluded that speaking assessment through Blackboard may provide a positive washback to students (Center for Applied Linguistics, 2021). This successful testing experience is a source of self-confidence and self-motivation not only for oral communication in the target language, but also for the development of technical and software-specific skills which lead to further successful online assessment.

\section{References}

Babo, R., Azevedo, A. \& Suhonen, J. (2015). Students' perceptions about assessment using an e-learning platform. Proceedings of 15th International Conference on Advanced Learning Technologies IEEE, 244-246. doi 10.1109/ICALT.2015.73

Center for Applied Linguistics. (2021). Foreign Language Assessment Directory. Retrieved April 30 ${ }^{\text {th }}, 2021$, from http://webapp.cal.org/FLAD

Englund, C., Olofsson, A.D. \& Price, L. (2017). Teaching with technology in Higher Education: Understanding conceptual change and development in practice. Higher Education Research \& Development,36(1), 73-87. dx.doi.org/10.1080/07294360.2016.1171300

González-Such, J., Jornet Meliá, J.M. y Bakieva, M. (2013). Consideraciones metodológicas sobre la evaluación de la competencia oral en L2. Revista electrónica de investigación educativa (REDIE), 15(3). ISSN 1607-4041

Hussein, E.T. (2016). The Effectiveness of Using Blackboard in Improving the English Listening and Speaking Skills of the Female Students at the University of Hail. Advances in Social Sciences Research Journal, 3(12) 81-93. dx.doi.org/10.14738/-assrj.312.2379 
Irawan, R. (2020). Exploring the strengths and weaknesses of teaching speaking by using LMS-Edmodo. ELTICS (English Language Teaching and English Linguistics) Journal, 5(1), ISSN: 2407-0742 1

Jordan, M.M \& Duckett, N.D. (2018). Universities confront 'Tech Disruption': Perceptions of student engagement online using two Learning Management Systems. The Journal of Public and Professional Sociology, 10(1), art.4

Mishra, J. (2014). Speaking activities for ESL learners of Odia vernacular schools: Planning, management and evaluation. Research Scholar, 2(4), 132-136.

Rodrigues, P.D. \& Vetahmani, M.E. (2015). The impact of online learning in the development of speaking skills. Journal of Interdisciplinary Research in Education, 5(1), 43-67. 